Portland State University

PDXScholar

7-25-1996

\title{
Quantification of Extraterrestrial Lava Flow Effusion Rates Through Laboratory Simulations
}

Tracy K.P. Gregg

Arizona State University

Jonathan H. Fink

Portland State University, jon.fink@pdx.edu

Follow this and additional works at: https://pdxscholar.library.pdx.edu/geology_fac

Part of the Geology Commons, and the Volcanology Commons

Let us know how access to this document benefits you.

\section{Citation Details}

Gregg, T. K., \& Fink, J. H. (1996). Quantification of extraterrestrial lava flow effusion rates through laboratory simulations. Journal of Geophysical Research: Planets (1991-2012), 101(E7), 16891-16900.

This Article is brought to you for free and open access. It has been accepted for inclusion in Geology Faculty Publications and Presentations by an authorized administrator of PDXScholar. Please contact us if we can make this document more accessible: pdxscholar@pdx.edu. 


\title{
Quantification of extraterrestrial lava flow effusion rates through laboratory simulations
}

\author{
Tracy K.P. Gregg ${ }^{1}$ and Jonathan H. Fink \\ Department of Geology, Arizona State University, Tempe
}

Abstract. We have used carefully controlled laboratory simulations to develop a model which relates lava flow morphology to effusion rate and rheology. Through comparisons with measured and estimated eruption rates on Earth, this approach allows us to constrain eruptive styles and compositions of extraterrestrial lava flows. By applying this model to lava flows on the Moon, Mars and Venus, we have determined that all the common flow morphologies (domes, folds and levees) on these planets could have been produced by basalt-like or andesite-like lavas through either continuous or episodic emplacement. The presence of more evolved magma compositions on other planets is not required to explain any of the observed lava flow morphologies.

\section{Introduction}

Effusive volcanism has modified the surfaces of all the solid planetary bodies in the solar system. Although Voyagers 1 and 2 captured spectacular images of active volcanic plumes on Jupiter's moon Io [e.g., Smith, 1990], the spacecraft's instruments could not resolve any associated active lava flows, so that Earth remains the only planet on which flowing lava has been observed. The composition and emplacement styles of lava flows reflect the interior workings of a planet: variables such as mantle composition, rates of magma genesis, magma chamber size and age, as well as magma rise rates through the planetary crust can be constrained through refined estimates of lava flow eruption and emplacement parameters [e.g., Cas and Wright, 1987; Head et al., 1992; Mouginis-Mark et al., 1992].

The potential of lava flows to reveal information about the evolution of an individual volcano or an entire planet has prompted the development of models which relate flow dimensions to lava rheology, composition, and effusion rate. Such efforts have been only partially successful because rheology and composition are not uniquely related; lava with a specific composition may experience a range of yield strengths and viscosities as. it cools. Furthermore, most existing models rely on questionable or empirical assumptions. Here, we present results from laboratory simulations designed to quantify the effects of effusion rate, cooling rate and underlying slope on lava flow morphology, and discuss how these experiments can be used to determine effusion rates of extraterrestrial lava flows. Comparison of these results with known eruption rates on Earth may in turn allow the rheologic properties and compositions of lavas on other planets to be constrained.

\footnotetext{
'Now at Department of Geology and Geophysics, Woods Hole Oceanographic Institution, Woods Hole, Massachusetts.
}

Copyright 1996 by the American Geophysical Union.

Paper number 96JE01254.

0148-0227/96/96JE-01254\$09.00

\section{Previous Work}

Currently available images from Mars, the Moon, and Venus have sufficient global resolution ( $200 \mathrm{~m} / \mathrm{pixel})$ to allow the lengths, widths and areas of lava flows to be measured; central channels, marginal levees and surface folds also can be resolved on selected extraterrestrial flows. Because obtaining these data is straightforward, the simplest models have attempted to relate them to effusion rate and other eruption parameters.

In a widely cited paper, Hulme [1974] related the dimensions of marginal levees to flow yield strength, assuming that lavas behave as isothermal Bingham fluids. He then compared yield strength and viscosity to estimate effusion rate:

$$
q=\frac{h_{c}^{3} g \rho \sin \beta S_{w}}{3 \eta_{p}}\left[\left(\frac{h}{h_{c}}\right)^{3}-1.5\left(\frac{h}{h_{c}}\right)^{2}+0.5\right]
$$

in which $q$ is effusion rate per unit width, $h$ is flow thickness, $h_{c}$ is critical flow thickness (below which a Bingham fluid will not flow), $g$ is gravitational acceleration, $\beta$ is the underlying slope, $S_{W}$ is the shear stress along the wall, and $\eta_{p}$ is plastic viscosity of the flow. Hulme [1974] used this model to estimate the composition and effusion rates of extraterrestrial lava flows. However, he assumed that the observed levees formed during a single episode of lateral spreading, without rubble accretion or repeated overflows of an established channel [Sparks et al., 1976], assumptions which cannot be unequivocally justified on the basis of planetary images. Furthermore, the yield strength and viscosity of a given flow may increase markedly as the lava cools and crystallizes [e.g., McBirney and Murase, 1984], making the relations between yield strength, silica content and effusion rate non-unique.

The Graetz number $(\mathrm{Gz})$, given by [e.g., Knudsen and Katz, 1979]

$$
\mathrm{Gz}=\frac{Q d}{\kappa x w}
$$

is a dimensionless parameter which relates the rate of heat loss from a flow to the rate of heat advection within the flow along its length, in which $Q$ is effusion rate, $d$ is flow thickness, $\mathrm{K}$ is thermal diffusivity, and $x$ and $w$ are length and width, 
respectively. On Earth, channelized basaltic lava flows apparently stop advancing when $\mathrm{Gz} \approx 300$ [Hulme and Fielder, 1977; Head and Wilson, 1986]. By substituting this value for $\mathrm{Gz}$, picking a value for $\kappa$ and using measured values for $d, x$ and $w, Q$ can be estimated. However, because this is an empirical relation derived specifically for terrestrial channelized basalts, it is unclear how well, if at all, it can be applied to lavas of other compositions, with different emplacement styles (for example, tube-fed flows [Pinkerton and Wilson, 1994]) or those emplaced in different planetary environments. More rigorous heat flux models have been presented recently [e.g., Crisp and Baloga, 1990; Dragoni et al., 1992], but these have not been used explicitly to determine eruption rates or other eruption parameters.

Jeffrey's equation relates flow viscosity to observed effusion rate and morphologic parameters, including underlying slope, and is given by [e.g., Nichols, 1939; Cas and Wright, 1987]

$$
\eta=\frac{g \rho h^{3} w \sin \beta}{n Q}
$$

in which $\eta$ is lava viscosity and $n$ is a constant equal to 3 for broad flows and 4 for narrow flows. Jeffrey's equation has been used extensively to estimate lava flow parameters [e.g., Nichols, 1939; Hulme, 1973]. By using measured values for $h$ and $w$, and assuming lava viscosity and density, an effusion rate can be inferred. However, Jeffrey's equation requires the questionable assumption that lava behaves as a Newtonian fluid, and it relies on channel depth, which is a difficult parameter to constrain.

\section{Laboratory Simulations}

Although the models described above provide starting points for understanding the eruption and emplacement conditions of extraterrestrial lava flows, they are based on unverifiable assumptions, or on empirical relations which are valid only for terrestrial flows, or require the presence of specific structures. These limitations prompted Fink and Griffiths [1990] to develop a more widely applicable, less empirical model to constrain the eruption and emplacement conditions of extraterrestrial lava flows. They used laboratory experiments, in which polyethylene glycol wax (PEG) was extruded at a constant rate into a tank filled with cold sucrose solution, to simulate lava flow morphologies. PEG was used because, like lava, it has a temperature-dependent viscosity.

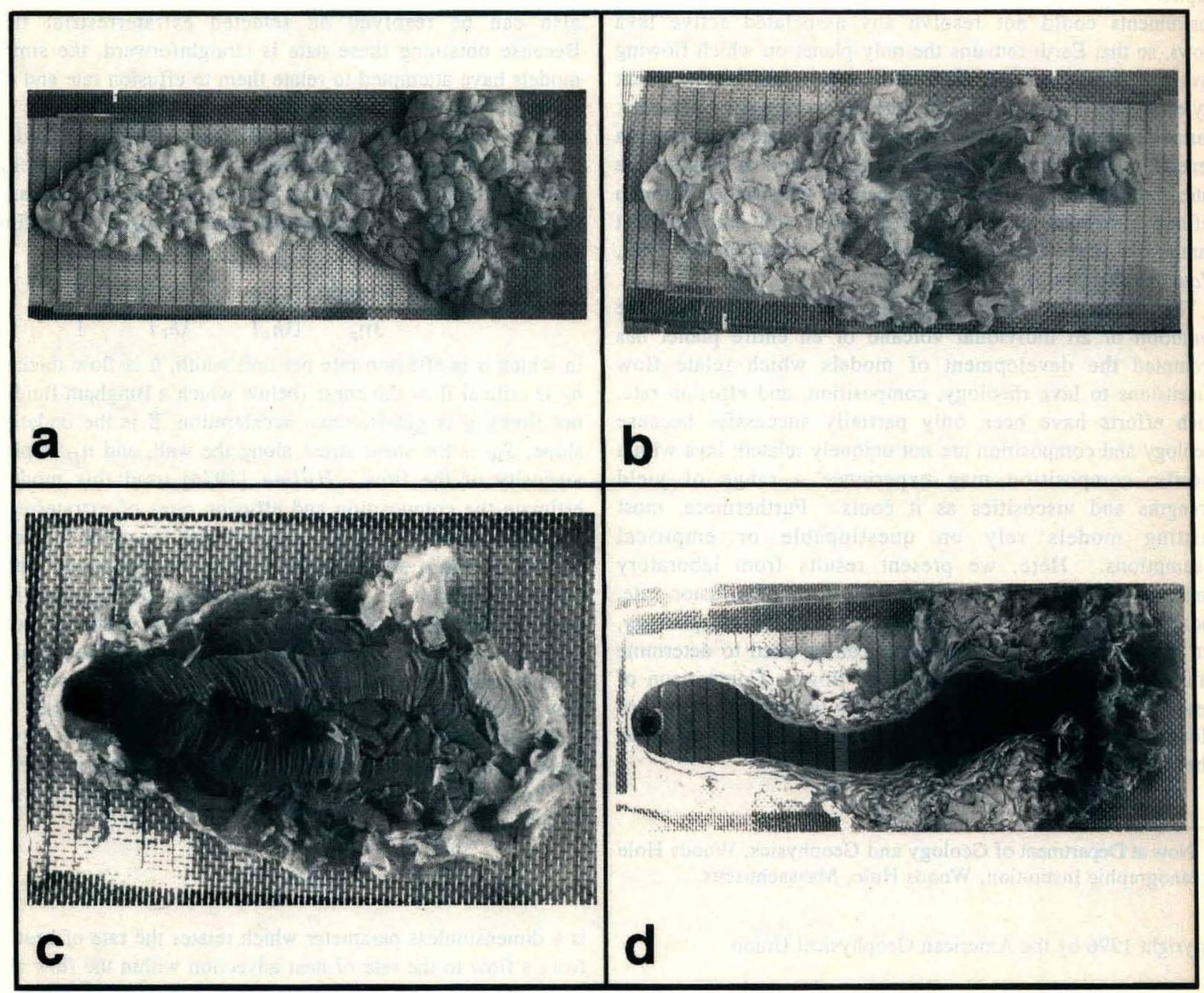

Figure 1. Laboratory flow types. Solid wax is light gray, and liquid wax is dark gray. The vent is to the left and the lines on the tank floor are $\sim 2 \mathrm{~cm}$ apart. Experiments shown were performed on gentle slopes $\left(\leq 10^{\circ}\right)$. Shown are (a) pillowed flow, (b) rifted flow, (c) folded flow, and (d) leveed flow. 
As PEG cools, it develops a solid crust which may deform in either a brittle or ductile manner, depending on the applied stresses and crust thickness [e.g., Fink and Griffiths, 1990].

By systematically varying both effusion rate and cooling rate, they generated a repeatable continuum of flow types. At the lowest extrusion rates and highest cooling rates, "pillowed" flows formed, in which the wax advanced by toes or buds, similar to subaerial "toey" pahoehoe flows or submarine pillowed flows (Figure 1a). As extrusion rate increased, and cooling rate decreased, pillowed flows gave way to "rifted" flows (plates of solid crust spread apart, separated by zones of liquid wax; Figure 1b). At higher extrusion rates, "folded" flows appeared, in which the surface crust deformed into a series of corrugations, with their long axes perpendicular to the flow direction (Figure 1c). Finally, the highest effusion rates and lowest cooling rates led to "leveed" flows in which nondeforming crust appeared only at the flow margin, leaving the interior liquid (Fig. 1d). These earlier studies established that each simulated flow can be quantified by a single dimensionless parameter, $\Psi$, which is the ratio of the timescale required for the surface of the flow to solidify $\left(t_{s}\right)$ versus the timescale for heat advection within the flow $\left(t_{a}\right)$ :

$$
\Psi=\frac{t_{s}}{t_{a}}
$$

For experiments performed on gentle slopes $\left(0 \leq \beta \leq 6^{\circ}\right)$, each flow type could be correlated with a specific range of $\Psi$ values: pillows form when $\Psi \leq 0.65$, rifts when $0.65<\Psi<2.8$, folds when $2.8<\Psi<6.4$, and levees when $\Psi>6.4$. These values of $\Psi$ at the morphological transitions are less than those reported in earlier publications [Fink and Griffiths, 1990, 1992; Griffiths and Fink, 1992; Gregg and Fink, 1995] owing to revised estimates of some of the important physical

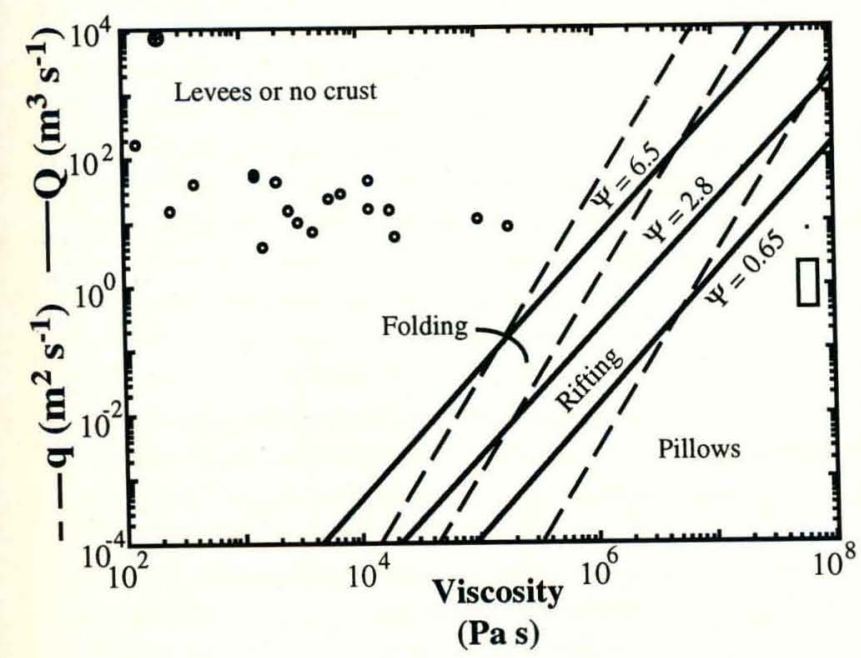

Figure 2. Relation between effusion rate and lava viscosity for observed lava flows on Earth. Dashed lines indicate transitional $\Psi$ values for linear effusion rates $\left(\mathrm{m}^{2} / \mathrm{s}\right)$, and solid lines indicate the same transitional $\Psi$ values for volumetric effusion rates $\left(\mathrm{m}^{3} / \mathrm{s}\right)$. Data shown are for channelized 1984 Mauna Loa flows (open circles), the October 1981 through August 1982 lobes of Mount St. Helens dacite dome (open rectangle), and the estimate for Columbia River basalt flows (circled cross). Note that the morphologic regimes predicted for each flow based on eruption parameters match well with the observed flow morphologies [modified from Fink and Griffiths, 1992].

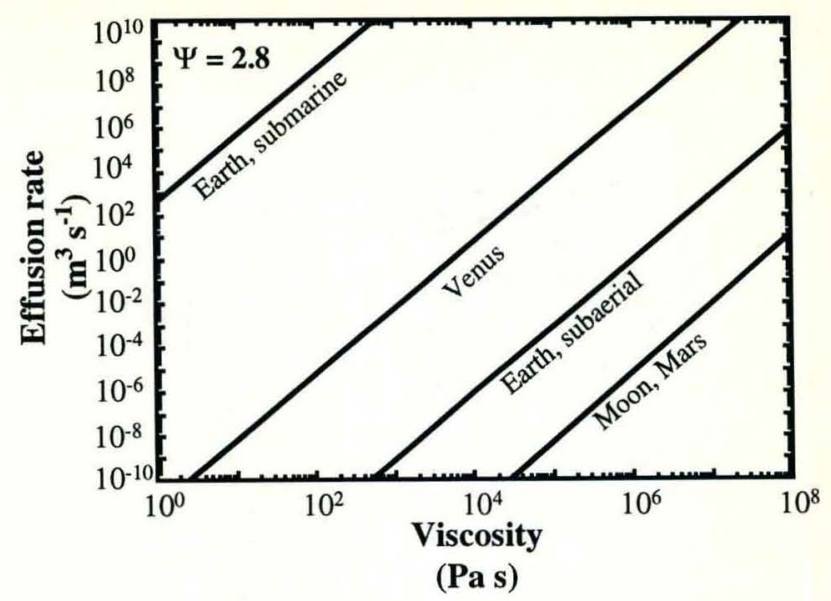

Figure 3. Effect of ambient conditions on lava flow morphologies. $\Psi$ values of 2.8 (rifting/folding transition for underlying slopes $<10^{\circ}$ ) are shown for basaltic lavas emplaced on Mars, Venus, the Moon, Earth, and Earth's seafloor. As cooling efficiently increases, transitional $\Psi$ values move downward and to the right.

variables. These revisions also apply to our earlier results and their applications, but these will be discussed elsewhere.

Gregg and Fink [1995] performed a series of similar experiments designed to examine the effect of underlying slope on morphology: PEG was extruded onto a tank floor tilted from $10^{\circ}$ to $60^{\circ}$ from the horizontal in $10^{\circ}$ increments. They obtained the same continuum of flow morphologies described by Fink and Griffiths [1990] (Figure 1), and concluded that increasing the underlying slope affects flow morphology in a manner similar to that of increasing the effusion rate. However, this influence is only detectable if the underlying slope is $>10^{\circ}$.

Because $\Psi$ incorporates all the key physical parameters of both an extrusion and its environment, these results are applicable to natural lava flows on Earth (Figure 2). For example, channelized Mauna Loa flows, for which eruption and emplacement parameters are known, have associated $\Psi$ values that are greater than 6.5 , as the model predicts for the leveed regime. Various lobes of the Mount St. Helens dactie dome are interpreted to have been emplaced through a rifting process, based on the presence of "crease structures" [Anderson and Fink, 1992] on their surfaces. This interpretation agrees with calculated $\Psi$ values of between 1 and 2.

These results can be applied to lava flows on other planets as well because $\Psi$ takes account of ambient conditions. The solidification timescale $t_{s}$ is dominated by the heat flux from the flow surface. This flux may be either primarily radiative (as on the Moon and Mars) or convective (as on Venus or for terrestrial submarine flows). These fluxes are given by [Griffiths and Fink, 1992]

$$
\begin{gathered}
F_{r}=\varepsilon \sigma\left(T_{c}^{4}-T_{a}^{4}\right) \\
F_{c}=\rho_{a} c_{a} \gamma\left(\frac{\mathrm{g} \alpha_{a} \kappa_{a}^{2}}{v_{a}}\right)^{1 / 3}\left(T_{c}-T_{a}\right)^{4 / 3}
\end{gathered}
$$

in which $F_{r}$ is radiative flux, $F_{C}$ is convective heat flux, $\varepsilon$ is lava emissivity, $\sigma$ is the Stephan-Boltzmann radiation constant, $T$ is temperature in Kelvin, $c$ is specific heat, $\alpha$ is the coefficient of thermal expansion, $\gamma$ is a constant 
Table 1. EruptionValues Used in Numerical Calculations

\begin{tabular}{|c|c|c|c|c|c|c|}
\hline $\begin{array}{c}\text { Eruption } \\
\text { Temperature, } \\
\text { K }\end{array}$ & $\begin{array}{c}\text { Glass Transition } \\
\text { Temperature, } \\
\text { K }\end{array}$ & $\begin{array}{c}\text { Thermal } \\
\text { Diffusivity, } \\
\mathrm{m}^{2} \mathrm{~s}^{-1}\end{array}$ & $\begin{array}{l}\text { Viscosity, } \\
\text { Pa s }\end{array}$ & $\begin{array}{l}\text { Density, } \\
\mathrm{kg} \mathrm{m}^{-3}\end{array}$ & $\begin{array}{l}\text { Heat Capacity, } \\
\qquad \mathrm{J} \mathrm{kg}^{-1} \mathrm{~K}^{-1}\end{array}$ & $\begin{array}{l}\text { Associated } \\
\text { Composition }\end{array}$ \\
\hline 1425 & 1000 & $5.0 \times 10^{-7}$ & $10^{2}$ & 2700 & 1200 & basalt $^{\mathrm{a}}$ \\
\hline 1300 & 900 & $3.0 \times 10^{-7}$ & $10^{5}$ & 2600 & 1125 & andesite ${ }^{b}$ \\
\hline 1200 & 850 & $2.0 \times 10^{-7}$ & $10^{7}$ & 2500 & 1050 & dacite \\
\hline 1100 & 800 & $1.4 \times 10^{-6}$ & $10^{9}$ & 2400 & 1000 & rhyolite $^{d}$ \\
\hline
\end{tabular}

${ }^{a}$ Mid-ocean ridge basalt [Griffiths and Fink, 1992]

${ }^{b}$ Mount Hood andesite [Murase and McBirney, 1973].

'From Anderson and Fink [1992].

${ }^{\mathrm{d}}$ Newberry rhyolite [Murase and McBirney, 1973].

approximately equal to $0.1, \kappa$ is thermal diffusivity, $v$ is kinematic viscosity, and the subscripts "c" and "a" refer to "crust" or flow surface, and "ambient," respectively. Figure 3 shows the effect of ambient conditions on lava flow morphologies; values used in these model calculations are shown in Table 1. Although Griffiths and Fink [1992] proposed that careful scaling of laboratory results could be used to constrain effusion rates of extraterrestrial lava flows, they only cited one illustrative example.

By correlating natural lava flow morphologies with laboratory flow types, and calibrating estimated $\Psi$ values with those calculated from observing active lava flows on Earth, we can assign a range of $\Psi$ values to a planetary lava flow. If the eruption temperature and viscosity of the flow are also known or assumed, effusion rates can be constrained. The coarseresolution altimetry data currently available for Mars, Moon, and Venus suggest that slopes $>10^{\circ}$ are rare on these planets, other than on fault scarps and some volcano flanks. We assume that the extraterrestrial flows observed in the present study were all emplaced on slopes $<10^{\circ}$.

\section{Method}

To estimate effusion rates for extraterrestrial lava flows, we first classify the observed morphology as pillows/domes, rifts, folds, or levees, which provides a range of experimentally determined $\Psi$ values. Because compositions are unknown for most extraterrestrial lava flows, a set of possible eruption parameters (such as eruption temperature, viscosity, and density), corresponding to various lava compositions (Table 2), are inserted into the model, allowing effusion rates to be graphically determined. These rates are then compared with terrestrial values, obtained from the literature, for lavas of similar compositions to assess the reasonableness of the model results.

For a line-source (fissure) eruption, linear effusion rate ( $q$ in $\mathrm{m}^{2} / \mathrm{s}$ ) can be determined by [Griffiths and Fink, 1992]

$$
q=\left(\Psi^{3}\right)\left(\frac{1}{t_{s}}\right)^{3}\left(\frac{\rho v}{g\left(\rho-\rho_{a}\right)}\right)^{2}
$$

For a point-source (central-vent) eruption, effusion rate $(Q$ in $\mathrm{m}^{3} / \mathrm{s}$ ) is given by

$$
Q=\left(\Psi^{4}\right)\left(\frac{1}{t_{s}}\right)^{4}\left(\frac{\rho v}{g\left(\rho-\rho_{a}\right)}\right)^{3}
$$

In both equations, $\Psi$ is obtained from the observed flow morphology. The timescale for solidification is calculated using the appropriate heat fluxes for the specific planetary environment (see (5) and Table 1). The last term in both equations is the rate at which heat would be advected within the flow owing to lateral spreading caused by gravitational forces alone. Vesiculation may cause the bulk density of a lava to vary by more than a factor of 2 ; however, examination of (6) demonstrates that the significance of absolute lava density is subordinate to the density contrast between the lava and its environment. Although our simulated flows are erupted through a point source, an underlying slope prohibits the formation of axially symmetric flows. Thus model results are most accurate when flows are scaled as line-source (fissure) eruptions, with the conduit diameter or the near-vent flow width being used as fissure length.

Table 2. Ambient Parameters Used in Numerical Calculations

\begin{tabular}{ccccccc}
\hline Planet & Temperature, & $\begin{array}{c}\text { Thermal } \\
\text { Expansion, } \\
\mathrm{K}^{-1}\end{array}$ & $\begin{array}{c}\text { Thermal } \\
\text { Diffusivity, } \\
\mathrm{m}^{2} \mathrm{~s}^{-1}\end{array}$ & $\begin{array}{c}\text { Kinematic } \\
\text { Viscosity, } \\
\mathrm{m}^{2} \mathrm{~s}^{-1}\end{array}$ & $\begin{array}{c}\text { Density, } \\
\mathrm{kg} \mathrm{m}^{-3}\end{array}$ & $\begin{array}{c}\text { Gravitational } \\
\text { Acceleration, } \\
\mathrm{m} \mathrm{s}^{-2}\end{array}$ \\
\hline Moon & 4 & -- & -- & -- & -- & 1.56 \\
Mars & 200 & $5.0 \times 10^{-3}$ & $7.2 \times 10^{-4}$ & $6.3 \times 10^{-5}$ & 0.2 & 3.72 \\
Venus & 730 & $1.3 \times 10^{-3}$ & $7.3 \times 10^{-7}$ & $4.5 \times 10^{-7}$ & 62.5 & 8.88 \\
Earth & 300 & $3.4 \times 10^{-3}$ & $2.3 \times 10^{-5}$ & $1.6 \times 10^{-5}$ & 1.2 & 9.78 \\
\hline
\end{tabular}

Values obtained from Carr [1981], Murray et al. [1981], Seiff [1983], Lide [1990] and Gregg and Greeley [1993]. Values for Mars and Venus were calculated assuming pure $\mathrm{CO}_{2}$ behaving as an ideal gas at $600 \mathrm{~Pa}$ and $9 \times 10^{6} \mathrm{~Pa}$, respectively, at the appropriate temperatures. 
Estimations of effusion rate are most sensitive to flow viscosity and eruption temperature (which strongly controls $t_{s}$; see (5)). Viscosity increases 7 orders of magnitude between "basaltic" and "rhyolitic" lavas (Table 1) and is cubed to determine effusion rate. Eruption temperature varies by only a factor of one-fifth between the lava types, but temperature strongly controls $t_{s}$ (see (5)), which is inversely cubed to estimate effusion rate. Finally, density varies by a factor of less than about one-third between lava types and is only cubed in equation (6a). Thus variations in lava density (due to increased vesiculation, for example) within a given flow type will have little effect on these effusion rate estimates, whereas viscosity changes may have order-of-magnitude effects.

\section{Extraterrestrial Lava Flow Morphologies and Effusion Rates}

To apply our model, the morphologies of extraterrestrial lava flows must be classified as pillows, rifts, folds, or levees. Folded flows and leveed flows can be readily identified on planetary surfaces. Although individual pillows, in the sense of small pahoehoe "toes," cannot be resolved on current planetary images, scaling of laboratory "pillowed" flows and comparison with terrestrial lava flows suggests that domes, composed of one or a few extrusions, correspond to $\Psi<0.65$. For example, the Mount St. Helens and Soufriere domes (for which effusion rate and flow viscosity are known) are associated with $\Psi$ values of $<0.65$. Therefore we assume that extraterrestrial lava domes may be considered as being within the pillowed regime.

Extrusions resembling lava domes $(\Psi<0.65)$ have been identified on the Moon, Mars, and Venus. On the Moon, the Marius Hills and the Gruithuisen Domes have been interpreted to be composed of evolved magmas [e.g., Smith, 1973] (Figure 4a). Martian domes, east of the Hellas basin, may be cinder cones, small, low shields, or lava domes [Carr, 1981] (Figure 5a). Several authors have proposed that the Venusian "pancake" domes (Figure 6a) are composed of evolved silicic lavas such as rhyolite [Head et al., 1991; Pavri et al., 1992]. Although rifting structures $(0.65<\Psi<2.8)$ are common in terrestrial lava lakes and rifted flows are widespread at terrestrial mid-ocean ridges [Gregg and Fink, 1995], they have not yet been observed on Mars or the Moon; we have identified a few possible rifted flows on Venus (Figure 6b). Folded flows $(2.8<\Psi<6.5)$ have been identified on the Moon, Mars and Venus. Folded lunar flows (Figure 4b), observed exclusively around impact craters, are thought to be composed of impact melt, material likely to be more viscous than mare lavas because of entrained clasts [Melosh, 1989]. Some Martian flows display surface fold wavelengths similar to those of terrestrial rhyolite flows (Figure 5b), and have been interpreted to be composed of evolved lavas [Fink, 1980]. Leveed flows $(\Psi>6.5)$ can be seen in the lunar maria (Figure 4c), on the flanks of Martian and Venusian shield volcanoes, as well as in Martian and Venusian volcanic plains (Figures $5 \mathrm{c}$ and $6 \mathrm{~d}$ ).

To estimate effusion rates from flow morphology using our model, both ambient and eruption parameters must be included in the calculations (see (5) and (6)). Ambient conditions are known for Mars [e.g., Carr, 1981], Venus [Seiff, 1983] and the Moon [e.g., Wilhelms, 1987], while eruption parameters (such as lava temperature, density, and viscosity) must be

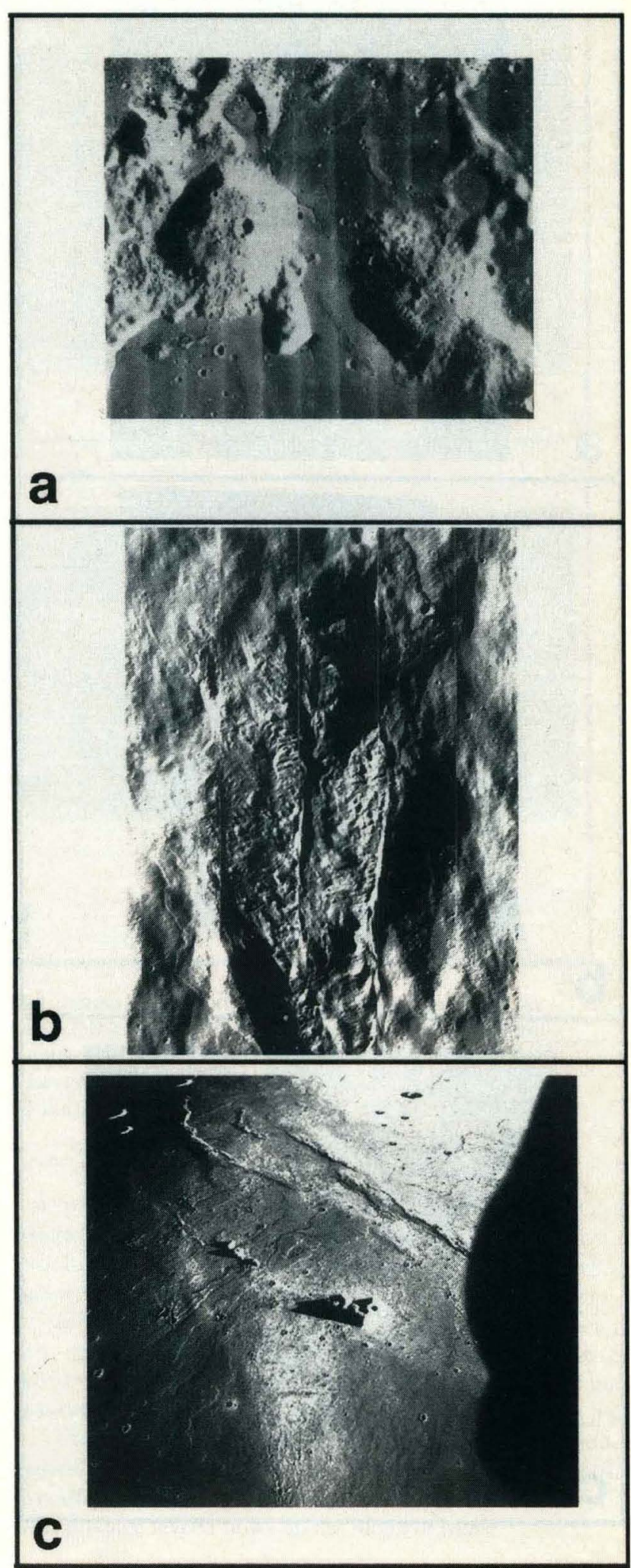

Figure 4. Lunar lava flow types as identified on Lunar Orbiter images. Field of view is given for each image. (a) Gruithuisen Domes $(\sim 10 \mathrm{~km})$. (b) Folded flows occur around some lunar impact craters, such as Tycho $(\mathrm{V} 127 \mathrm{H} ; \sim 5 \mathrm{~km})$ and are probably composed of impact melt. (c) Channelized flows are observed in the Imbrium basin $(\sim 300 \mathrm{~km})$. 


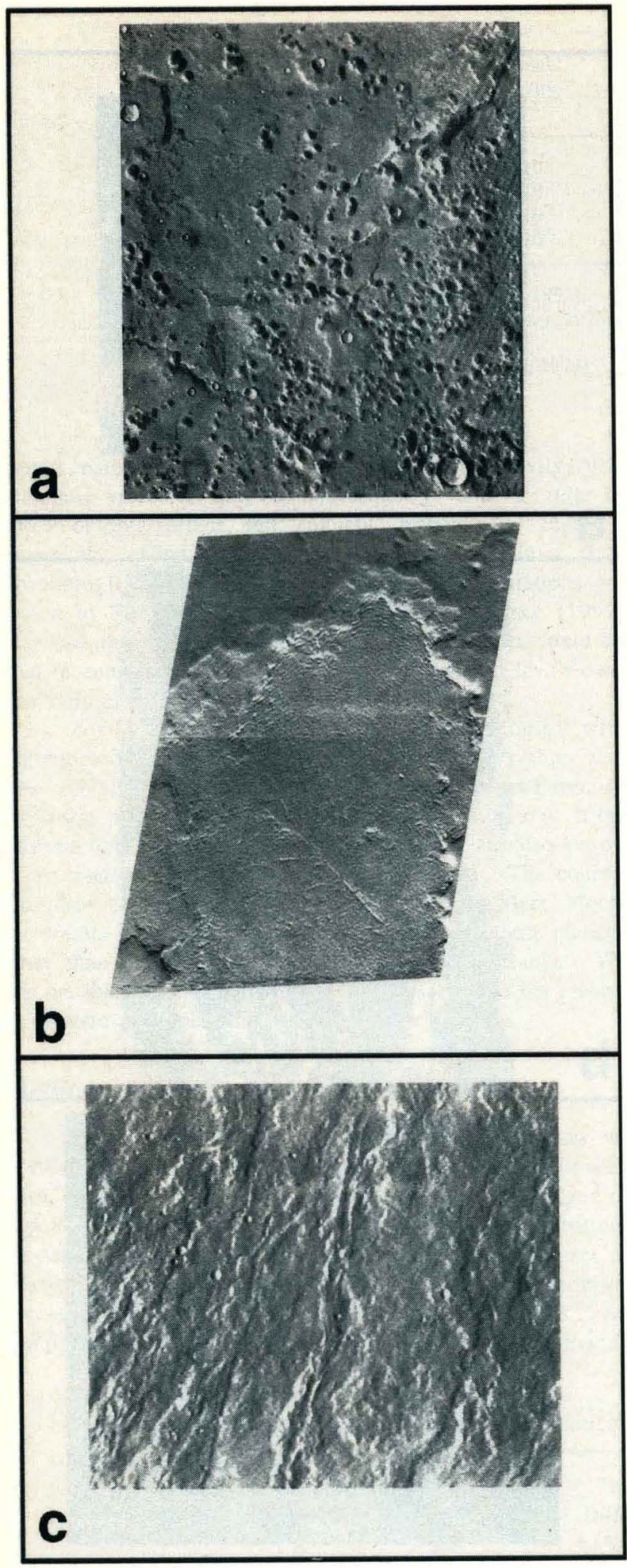

Figure 5. Martian lava flow types as identified from Viking Orbiter images. Approximate field of view is given for each image. (a) Small domes southwest of Hellas (VO 586B34; 50 $\mathrm{km}$ ); (b) folded flows near Arsia Mons (VO 731A03; $10 \mathrm{~km}$ ); (c) leveed flows on the flanks of Ascreaus Mons, Mars (VO401B16; 50 km). assumed for Martian and Venusian lavas, as well as for most lunar flows. We calculate effusion rates associated with each morphologic type for various lava parameters which can be related to a range of terrestrial lava compositions (Table 2). This produces a series of plots of effusion rate versus lava viscosity, which are used to graphically determine effusion rate. Because these effusion rate estimates strongly depend on lava viscosity, we compare them to observed and calculated rates for terrestrial eruptions assuming typical lava viscosities [Murase and McBirney, 1973] to assess the reasonableness of the model results. Comparison with terrestrial rates is justified because effusion rate is controlled primarily by lava viscosity and thermal diffusivity, conduit geometry, and the density contrast between the magma and the surrounding material through which it ascends [Wilson and Head, 1981]. Thus specific magma and conduit properties should result in similar effusion rates on the terrestrial planets [Wilson and Head, 1981]. In the following discussion, the words "basaltic," "andesitic," etc., refer to the set of properties (viscosity, density, thermal conductivity, temperature) commonly associated with those compositions for terrestrial flows, and are not intended explicitly to define a lava composition (Table 2).

\section{Results}

Representative calculations of effusion rates for Venus and Mars are shown graphically in Figure 7; results for lunar flows are indistinguishable from those of Martian flows. Values obtained for the Moon and Mars are similar because radiative cooling dominates over convective cooling on both planets [Griffiths and Fink, 1992], and the ambient temperatures ( $4 \mathrm{~K}$ on the Moon and $\sim 200 \mathrm{~K}$ on Mars) are both far below lava solidification points $(\sim 800 \mathrm{~K}-1000 \mathrm{~K})$. The densely stippled region on the plot defines observed or calculated effusion rates for the associated lava types for terrestrial eruptions; the more lightly stippled regions define a range of eruption rates possibly attained by terrestrial flood basalts (at one extreme) and a theoretical extension of effusion rates obtained for more viscous rhyolitic lavas (at the other extreme).

Formation of domes on the Moon, Mars and Venus requires an excessively low effusion rate $\left(<10^{-6} \mathrm{~m}^{2} / \mathrm{s}\right)$ if a basaltic composition $\left(\eta=10^{2} \mathrm{~Pa} \mathrm{~s}\right)$ is assumed; however, if an andesitic composition ( $\eta=10^{6} \mathrm{~Pa} s$ ) is invoked, the calculated maximum effusion rates $\left(10 \mathrm{~m}^{3} / \mathrm{s}\right)$ are similar to those observed for terrestrial andesite flows. This may indicate either that the domes are composed of andesite or that the extremely low effusion rate implied by our model actually reflects a time-averaged, episodic emplacement of basaltic lava [e.g., Fink and Bridges, 1995]. Alternatively, the domes may be composed of basaltic lava with a viscosity of $\sim 10^{5}$ to $10^{6} \mathrm{~Pa}$ s. This relatively high viscosity could be reached in a basalt flow containing $>30$ vol\% crystals or vesicles [Spera et al., 1988; Pinkerton and Stevenson, 1992], although such a high volume of vesicles within a basaltic lava is unlikely on Venus [Head and Wilson, 1986; Hess and Head, 1990]. "Rhyolitic" or "dacitic" magma may have produced the Venusian domes with effusion rates similar to those observed and estimated for terrestrial rhyolite or dacite flows.

Rifted flows, tentatively identified only on Venus, could be produced by relatively low effusion rate basaltic $\left(\eta=10^{2} \mathrm{~Pa} \mathrm{~s}\right)$ 


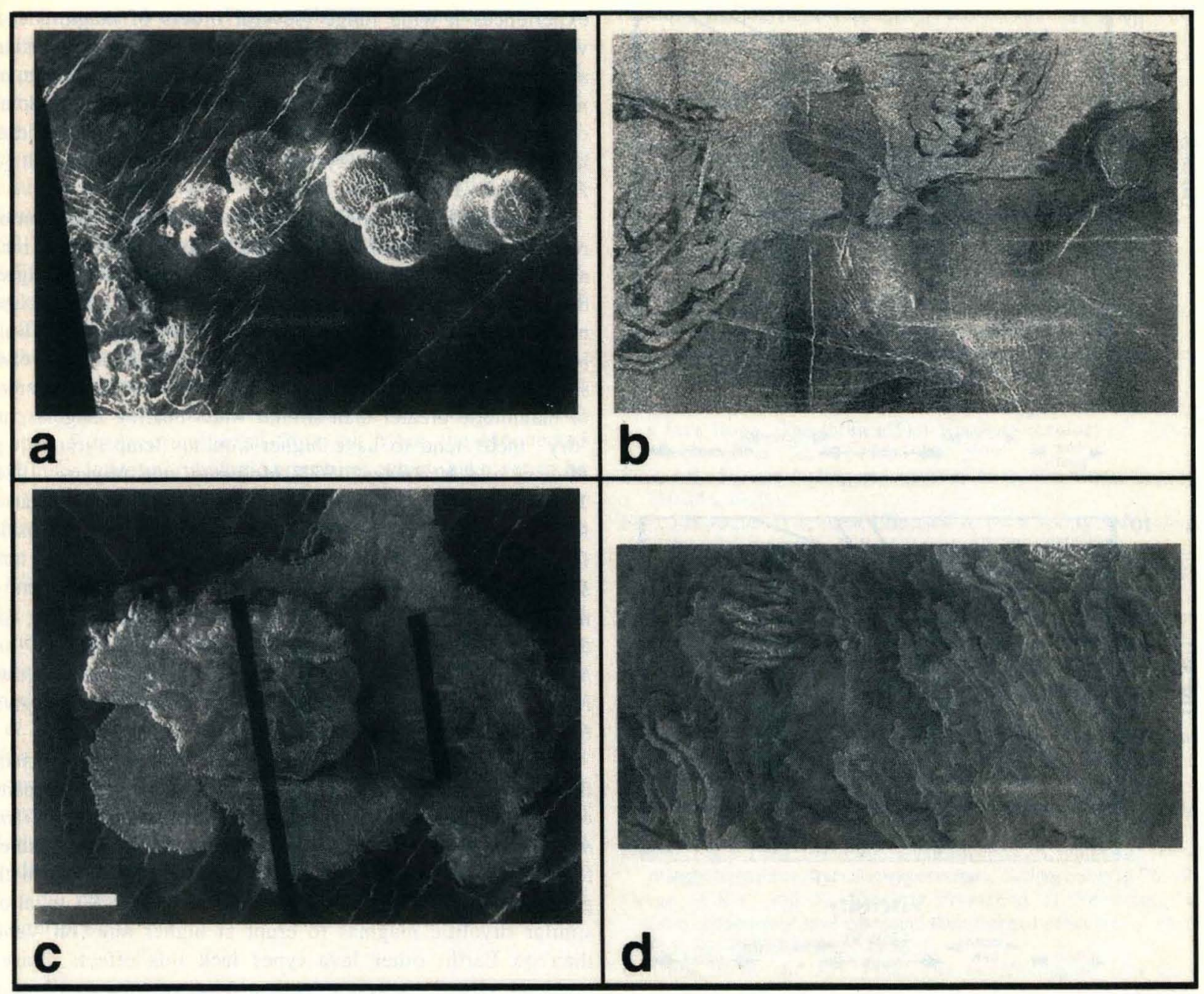

Figure 6. Venusian lava flow types identified on Magellan images. Approximate field of view is given for each image. (a) Venusian pancake domes (FMIDRP 30S009; 250 km). (b) Flows corresponding to the rifting regime in the laboratory have been identified only on Venus (FMIDRP 05S205; 200 km). (c) Maheuea Tholus, a folded flow (FMIDRP 37S164; 400 km). (d) Leveed flows are common around Venusian shield volcanoes and in some lava plains (FMIDRP 75N237; $300 \mathrm{~km}$ ).

eruptions $\left(10^{-3} \mathrm{~m}^{2} / \mathrm{s}<q<10^{-1} \mathrm{~m}^{2} / \mathrm{s}\right)$ or emplacement of andesitic $\left(\eta=10^{6} \mathrm{~Pa} \mathrm{~s}\right)$ lavas at more typical effusion rates $\left(10^{-2} \mathrm{~m}^{2} / \mathrm{s}<q<1 \mathrm{~m}^{2} / \mathrm{s}\right)$. We favor the former interpretation, as elemental data from the Venera Landers, and general volcano morphology, suggest a mafic composition [Nikolayeva, 1990; Head et al., 1992]. Effusion rates required to produce Venusian rifted flows from dacitic or rhyolitic lavas are higher than what is observed or estimated for nonexplosive emplacement of these lavas on Earth.

Folded flows on the Moon, Mars, and Venus display fold dimensions most similar to those observed on terrestrial rhyolite flows [Fink, 1980; Theilig and Greeley, 1986; Moore et al., 1992]. Our model suggests, however, that unreasonably high effusion rates (as compared to observed or calculated terrestrial values) would be required to produce these morphologies from rhyolitic or dacitic lavas on Venus. Alternatively, andesitic lavas could generate folded flows on all of the terrestrial planets with effusion rates similar to those observed for terrestrial andesite eruptions $\left(1 \mathrm{~m}^{2} / \mathrm{s}<q<10\right.$ $\left.\mathrm{m}^{2} / \mathrm{s}\right)$.
A wide range of effusion rates is capable of producing basaltic leveed flows on all of the terrestrial planets. This is consistent with observations of Mars and Venus, where channelized lavas are among the most common flow types. It is possible that they were once more common on the Moon as well, but are no longer recognizable due to erosion by micrometeorite impacts [e.g., Wilhelms, 1987]. Minimum effusion rates as low as $\sim 10^{-6} \mathrm{~m}^{2} / \mathrm{s}$ (for $\eta=10^{2} \mathrm{~Pa} \mathrm{~s}$ ) or as high as $\sim 10^{5} \mathrm{~m}^{2} / \mathrm{s}$ (for $\eta=10^{8} \mathrm{~Pa}$ s) are likely to produce channelized flows on Venus. For lavas with similar viscosities, minimum effusion rates of $\sim 10^{-6}$ to $\sim 10^{4} \mathrm{~m}^{2} / \mathrm{s}$ could produce leveed flows on the Moon or Mars.

\section{Discussion and Implications}

The model presented here does not explicitly assume lava composition. Rather, it uses a range of eruption parameters (Table 2) which, by comparison with observed and estimated terrestrial eruption parameters, imply a lava composition. 
lavas: Implications of numerical modeling results, J. Volcanol. Geotherm. Res., 53, 27-46, 1992.

McBirney, A.R., and T. Murase, Rheological properties of magmas, Annu. Rev. Earth Planet. Sci., 12, 337-357, 1984.

Melosh, J.A., 1989, Impact Cratering: A Geologic Process, 245 pp., Oxford Univ. Press, New York.

Moore, H.J., J.J. Plaut, P.M. Schenk, and J.W. Head, An unusual volcano on Venus, J. Geophys. Res., 97, 13,479-13,494, 1992.

Mouginis-Mark, P.J., L. Wilson, and M.T. Zuber, The physical volcanology of Mars, in Mars, edited by H.H. Kieffer, B.M. Jakosky, C.W. Snyder, and M.S. Matthews, pp. 424-452, Univ. of Ariz. Press, Tucson, 1992.

Murase, T., and A.R. McBirney, Properties of some common igneous rocks and their melts at high temperatures, Geol. Soc. Am. Bull., 84, 3563-3592, 1973.

Murray, B., M.C. Malin, and R. Greeley, Earthlike Planets: Surfaces of Mercury, Venus, Earth, Moon, Mars, 387 pp., W.H. Freeman, New York, 1981.

Newhall, C.G., and W.G. Melson, Explosive activity associated with the growth of volcanic domes, J. Volcanol. Geotherm. Res., 17, 111-131, 1983.

Nichols, B.L., Viscosity of lava, J. Geol., 47, 290-302, 1939.

Nikolayeva, O.V., Geochemistry of the Venera 8 material demonstrates the presence of continental crust on Venus, Earth Moon Planets, 50/51, 329-341, 1990

Pavri, B., J.W. Head, K.B. Klose, and L. Wilson, Steep-sided domes on Venus: Characteristics, geologic setting, and eruption conditions from Magellan data, J. Geophys. Res., 97, 13,445-13,478, 1992.

Pinkerton, H., and R.J. Stevenson, Methods of determining the rheological properties of magmas at sub-liquidous temperatures, $J$. Volcanol. Geotherm. Res., 53, 47-66, 1992.

Pinkerton, H., and L. Wilson, Factors controlling the lengths of channelfed lava flows, Bull. Volcanol., 56, 108-120, 1994.

Rose, W.I., Volcanic activity at Santiaguito volcano, 1976-1984, in The Emplacement of Silicic Domes and Lava Flows, edited by J.H. Fink, Geol. Soc. Am. Spec. Pap. 212, 17-28, 1987.

Seiff, A., 1983, Thermal structure of the atmosphere of Venus, in Venus, edited by D.M. Hunten, L. Colin, T.M. Donahue and V.I. Moroz, pp. 215-279, Univ. of Ariz. Press, Tucson.

Shaw, H.R., and D.A. Swanson, Eruption and flow rates of flood basalts, in Proceedings of Second Columbia River Basalt Symposium, pp.
271-299, Eastern Washington State College Press, Cheney, Washington, 1970.

Smith, B.A., The Voyager encounters, in The New Solar System, edited by J.K. Beatty and A. Chaikin, pp. 107-130, Cambridge Univ. Press, New York, 1990.

Smith, E.I., Identification, distribution and significance of lunar volcanic domes, Moon, 6, 3-31, 1973.

Sparks, R.S.J., H. Pinkerton, and G. Hulme, Classification and formation of lava levees on Mount Etna, Sicily, Geology, 4, 269-271, 1976.

Spera, F.J., A. Borgia, and J. Strimple, Rheology of melts and magmatic suspensions, 1. Design and calibration of concentric cylinder viscometer with application to rhyolitic magma, J. Geophys. Res., 93, 10,273-10,294, 1988.

Taylor, G.A.M., 1958, The 1951 Eruption of Mount Lamington, Papua, Bur. of Min. Resour. Geol. and Geophys. Bull. 38, Australian Government Publishing Service, Canberra.

Theilig, E., and R. Greeley, Lava flows on Mars: Analysis of small surface features and comparisons with terrestrial analogs, Proc. Lunar Planet. Sci. Conf. 17th, Part 1, J. Geophys. Res. 91, suppl., E193-E206, 1986.

Wilhelms, D.E., The geologic history of the Moon, U S. Geol. Surv. Prof. Pap. 1348, 302 pp, 1987.

Williams, H., and A.R. McBirney, Volcanology, 397 pp., Freeman, Cooper, San Francisco, Calif., 1979.

Wilson, L., and J.W. Head, Ascent and eruption of basaltic magma on the Earth and Moon, J. Geophys. Res., 86, 2987-3001, 1981.

Wolfe, E. W., C. A. Neal, N. G. Banks, and T. J. Duggan, Geologic observations and chronology of eruptive events, in The Puu $\mathrm{O}_{0}$ eruption of Kilauea volcano, Hawaii: Episodes 1 through 20, January 3, 1983, through June 8, 1984, edited by E. W. Wolfe, U.S. Geol.Surv. Prof. Pap. 1463, 251 pp., 1988.

J.H. Fink, Department of Geology, Box 871404, Arizona State University, Tempe, AZ 85287-1404.

T.K.P. Gregg, Department of Geology and Geophysics, Woods Hole Oceanographic Institution, Woods Hole, MA 02543. (e-mail: tgregg@whoi.edu)

(Received July 3, 1995; revised April 11, 1996; accepted April 17, 1996.) 